\title{
Factors associated with right ventricular dilatation and dysfunction in patients with chronic pulmonary regurgitation after repair of tetralogy of Fallot: Analysis of magnetic resonance imaging data from 218 patients
}

\author{
Cheul Lee, MD, PhD, ${ }^{a}$ Chang-Ha Lee, MD, ${ }^{a}$ Jae Gun Kwak, MD, ${ }^{a}$ Seong-Ho Kim, MD, ${ }^{b}$ \\ Woo-Sup Shim, MD, ${ }^{\mathrm{b}}$ Sang Yun Lee, MD, ${ }^{\mathrm{b}}$ So-Ick Jang, MD, ${ }^{\mathrm{b}}$ Su-Jin Park, MD, ${ }^{\mathrm{b}}$ and Yang Min Kim, MD
}

Objective: The aim of the present study was to identify the factors associated with right ventricular (RV) dilatation and dysfunction in patients with chronic pulmonary regurgitation (PR) after repair of tetralogy of Fallot.

\begin{abstract}
Methods: From April 2002 to June 2013, 218 patients with repaired tetralogy of Fallot underwent magnetic resonance imaging; 165 (76\%) underwent transannular repair and $36(17 \%)$ underwent nontransannular repair. Linear regression analyses were used to identify the predictors for RV end-diastolic volume index (EDVI), end-systolic volume index (ESVI), and ejection fraction.
\end{abstract}

\begin{abstract}
Results: On univariable analysis, male sex, ventricular septal defect (VSD) closure through the right ventricle, larger pulmonary artery index, and greater PR fraction were associated with greater RV volume indexes. Multivariable analyses identified male sex $(\beta=17.55, P<.001$ for RV EDVI; $\beta=14.08, P=.001$ for RV ESVI), VSD closure through RV $(\beta=8.49, P=.048$ for RV ESVI), longer interval since repair $(\beta=1.29$, $P=.014$ for RV EDVI), and greater PR fraction $(\beta=1.92, P<.001$ for RV EDVI; $\beta=1.38, P<.001$ for RV ESVI) as independent predictors for greater RV volume indexes. On univariable analysis, male sex, VSD closure through the right ventricle, and greater PR fraction were associated with a lower RV ejection fraction. Multivariable analysis identified male sex $(\beta=-3.10, P=.018)$, VSD closure through the right ventricle $(\beta=-3.05, P=.020)$, and greater PR fraction $(\beta=-0.27, P<.001)$ as independent predictors for a lower $\mathrm{RV}$ ejection fraction.
\end{abstract}

Conclusions: Male sex, VSD closure through the right ventricle, longer interval since repair, and greater PR fraction were independent predictors of RV dilatation after tetralogy of Fallot repair. Male sex, VSD closure through the right ventricle, and greater PR fraction were also independent predictors of RV dysfunction. (J Thorac Cardiovasc Surg 2014;148:2589-96)

Repair of tetralogy of Fallot (TOF) is being performed with very low operative mortality, and the patients with repaired TOF can be expected to have excellent long-term survival. ${ }^{1,2}$ However, a substantial number of patients will be exposed to chronic pulmonary regurgitation (PR) owing to the loss of pulmonary valve competency at the repair. The resultant chronic volume overload can lead to right ventricular (RV) dilatation, biventricular dysfunction, heart failure symptoms, arrhythmias, and sudden death. ${ }^{3}$ Pulmonary valve

\footnotetext{
From the Departments of Thoracic and Cardiovascular Surgery, ${ }^{\mathrm{a}}$ Pediatric Cardiology, ${ }^{\mathrm{b}}$ and Radiology, ${ }^{\mathrm{c}}$ Cardiovascular Center, Sejong General Hospital, Bucheon, Republic of Korea.

Disclosures: Authors have nothing to disclose with regard to commercial support.

Read at the 94th Annual Meeting of The American Association for Thoracic Surgery, Toronto, Ontario Canada, April 26-30, 2014.

Received for publication April 9, 2014; revisions received July 9, 2014; accepted for publication July 14, 2014; available ahead of print Aug 28, 2014

Address for reprints: Cheul Lee, MD, PhD, Department of Thoracic and Cardiovascular Surgery, Seoul St Mary's Hospital, The Catholic University of Korea, 222, Banpo-daero, Seocho-gu, Seoul, Republic of Korea (E-mail: tscheul@hanmail. net).

$0022-5223 / \$ 36.00$

Copyright (C) 2014 by The American Association for Thoracic Surgery

http://dx.doi.org/10.1016/j.jtcvs.2014.07.051
}

replacement (PVR) has become a common practice to avoid the dreadful sequelae of chronic PR, although this procedure is also not without problems. ${ }^{4-8}$

The factors associated with RV dilatation and dysfunction in patients with chronic PR after TOF repair are not completely understood. Understanding these factors could help identify those patients who need more careful follow-up to determine the optimal timing of PVR. Also, understanding these factors might help clarify the optimal surgical management of TOF for better long-term outcomes. Magnetic resonance imaging (MRI) is currently the reference standard for evaluating $\mathrm{RV}$ volumes and function in patients with chronic PR after TOF repair. ${ }^{9,10}$ The aim of the present study was to identify the factors associated with RV dilatation and dysfunction in patients with chronic PR after repair of TOF by analyzing the MRI data obtained long term after repair.

\section{METHODS}

The institutional review board of Sejong General Hospital approved the present retrospective study and waived the need for individual patient consent. 


$$
\begin{aligned}
& \text { Abbreviations and Acronyms } \\
& \text { EDVI }=\text { end-diastolic volume index } \\
& \text { EF }=\text { ejection fraction } \\
& \text { MRI }=\text { magnetic resonance imaging } \\
& \text { PAI }=\text { pulmonary artery index } \\
& \text { PR }=\text { pulmonary regurgitation } \\
& \text { PVR } \\
& \text { RV pulmonary valve replacement } \\
& \text { RVOTO }=\text { right ventricular } \\
& \text { TAP }=\text { transannular patch } \\
& \text { TOF } \\
& \text { VSD }=\text { tetralogy of Fallot } \\
&
\end{aligned}
$$

\section{Study Population and Data Collection}

By searching the database of our institution, we identified 218 study patients with repaired TOF who had undergone MRI for evaluation of PR from April 2002 to June 2013. Of these, 24 patients had undergone repair at other hospitals. Approximately 1255 patients had undergone TOF repair during the same period (from 1982 to 2006) when the study population had undergone TOF repair. The prescription of MRI was at the discretion of the cardiologist. Excluded from the present study were patients with other significant confounding congenital heart defects (eg, atrioventricular septal defect, major aortopulmonary collateral arteries), right ventricle to pulmonary artery conduits, significant (at least moderate) regurgitation of other valves, and poor MRI quality with resultant inaccurate volumetric data. In patients with serial MRI examinations, we used the most recent MRI data for the analyses. Data were obtained by a review of the medical records. Echocardiographic, electrocardiographic, and cardiopulmonary exercise test data within 1 year of the MRI study were obtained for analysis. The characteristics of the study patients are listed in Table 1.

\section{Cardiac MRI}

MRI studies were performed with a 1.5-Tesla Gyroscan Intera CV system (Philips Medical Systems, Best, The Netherlands). Biventricular volumetric analysis was performed using Extended MR Workspace software (Philips Medical Systems). The details of the MRI protocol used in our institution for the assessment of patients with repaired TOF have been described previously. ${ }^{4}$ A single observer (Y.M.K.) performed all measurements of the branch pulmonary artery size, and the diameters of the narrowest portion of the branch pulmonary arteries were measured. From these measurements, the pulmonary artery index (PAI) was calculated as follows: (cross-sectional area of the right pulmonary artery $\left[\mathrm{mm}^{2}\right]+$ cross-sectional area of the left pulmonary artery $\left.\left[\mathrm{mm}^{2}\right]\right) /\left(\right.$ body surface area $\left[\mathrm{m}^{2}\right]$ ).

\section{Follow-up}

The follow-up data were considered complete if the patient's status had been determined after January 2012. The mean duration of follow-up since repair was $19.5 \pm 4.9$ years, and $77.1 \%$ of the study patients had complete follow-up data. The follow-up completeness, measured by calculating the Clark index, ${ }^{11}$ was $93.6 \%$.

\section{Statistical Analysis}

The data were tested for normal distribution using the KolmogorovSmirnow test and histogram. Data are presented as frequencies and percentages, mean \pm standard deviation, or median and range, as appropriate. Comparisons between independent groups were performed using the independent samples $t$ test, Mann-Whitney $U$ test, or chi-square test, as appropriate. Multiple linear regression analysis (backward method) was used to identify the independent predictors for the RV end-diastolic volume index (EDVI), RV end-systolic volume index, and RV ejection fraction (EF). The potential predictors examined were sex, history of palliation, age at repair, repair type, route of ventricular septal defect (VSD) closure, interval since repair, presence of RV outflow tract obstruction (RVOTO), PAI, and PR fraction. Patients with any missing data for these variables were excluded, and 160 patients were included in the linear regression analysis. Univariable predictors with $P<.15$ were entered as potential independent predictors on multivariable analysis. The Statistical Package for Social Sciences, version 18.0 (SPSS Inc, Chicago, Ill) was used for statistical analysis.

\section{RESULTS}

\section{Echocardiographic, Electrocardiographic, and Exercise Test Data at MRI Examination}

Echocardiographic data were available for 193 patients $(88.5 \%)$. The grade of tricuspid regurgitation was none in 23 patients, trivial in 74, mild in 95, and not available in 1. RVOTO was defined as a peak pressure gradient $\geq 25$ $\mathrm{mm} \mathrm{Hg}$. Ten patients $(5.2 \%)$ had RVOTO, and the median peak pressure gradient was $34 \mathrm{~mm} \mathrm{Hg}$ (range, 27-120). Electrocardiographic data were available for 141 patients (64.7\%). The mean QRS duration was $141 \pm 27 \mathrm{~ms}$, and 6 patients had QRS duration $\geq 180 \mathrm{~ms}$. The cardiopulmonary exercise test data were available for 78 patients $(35.8 \%)$, and the mean peak oxygen consumption was $29 \pm 7 \mathrm{~mL} / \mathrm{kg} / \mathrm{min}(70 \% \pm 16 \%$ of the predicted value $)$.

\section{Analyses of MRI Data (Predictors for RV Dilatation and Dysfunction)}

The MRI data for the entire study population are listed in Table 2. As determined on univariable analysis, male sex, VSD closure through the right ventricle, larger PAI, and greater PR fraction were associated with greater RV volume indexes. The multivariable analyses identified male sex, VSD closure through the right ventricle, a longer interval since repair, and greater PR fraction as independent predictors of greater RV volume indexes (Tables 3 and 4). As determined from the univariable analyses, male sex, VSD closure through the right ventricle, and greater PR fraction were associated with a lower RV EF. Multivariable analysis identified male sex, VSD closure through the right ventricle, and greater $\mathrm{PR}$ fraction as independent predictors for a lower RV EF (Table 5).

\section{Clinical Outcomes}

PVR was performed in 108 patients $(49.5 \%)$. The median age at PVR was 19.2 years (range, 7.1-44.3), and the mean interval between TOF repair and PVR was $16.3 \pm$ 4.9 years. The operative mortality after PVR was $0.9 \%$ (1 of 108). The results of a comparison between the patients who had undergone PVR and those who had not undergone PVR are presented in Table 6. Four patients developed atrial tachyarrhythmia during follow-up. No late death occurred in the entire study population, except for the PVR mortality case. 
TABLE 1. Patient characteristics

\begin{tabular}{lc}
\hline \multicolumn{1}{c}{ Variable } & Value \\
\hline Male sex & $120(55)$ \\
Palliation before repair & $24(11)$ \\
Age at repair & \\
$\quad$ Median & $1.7 \mathrm{y}$ \\
$\quad$ Range & $12 \mathrm{~d}$ to $33.5 \mathrm{y}$ \\
Repair type & \\
TAP & $165(76)$ \\
Non-TAP & $36(17)$ \\
No information & $17(8)$ \\
Route of VSD closure & \\
RV & $98(45)$ \\
RA & $73(33)$ \\
No information or other & $47(22)$ \\
Age at MRI (y) & $18.8 \pm 7.0$ \\
Interval between repair and MRI (y) & $15.8 \pm 4.8$ \\
Weight at MRI (kg) & $52.7 \pm 15.1$ \\
BSA at MRI (m $\left.{ }^{2}\right)$ & $1.52 \pm 0.28$ \\
NYHA functional class at MRI & \\
I & $128(59)$ \\
II & $81(37)$ \\
III & $2(1)$ \\
No information & $7(3)$ \\
\hline Data presented as n (\%) or mean \pm standard deviation. TAP, Transannular patch; \\
$V S D$, ventricular septal defect; $R V$, right ventricle; $R A$, right atrium; $M R I$, magnetic \\
resonance imaging; $B S A$, body surface area; $N Y H A$, New York Heart Association.
\end{tabular}

\section{DISCUSSION}

The well-documented long-term sequelae associated with chronic PR after TOF repair have emerged as great challenges for clinicians. ${ }^{3,10}$ The response of the right ventricle to chronic PR has varied among patients with repaired TOF, and the factors associated with RV dilatation and dysfunction in these patients are not completely understood. Previous studies have tried to identify the risk factors for PVR, a surrogate outcome for $\mathrm{RV}$ dilatation and dysfunction. ${ }^{12-14,16}$ Because PVR is still an evolving procedure in terms of its indications and optimal timing, objective measures of the RV volume and function are necessary to better elucidate the factors associated with RV dilatation and dysfunction. Our study identified independent predictors for RV dilatation and dysfunction in patients with chronic PR after TOF repair by analyzing the data obtained with MRI, a reference standard for evaluating the RV volume and function.

In the present study, male sex was identified as an independent predictor for RV dilatation and dysfunction. This finding is in accordance with the finding from the study by Spiewak and colleagues, ${ }^{15}$ which found that male sex was an independent predictor for larger RV EDVI. Kogon and colleagues ${ }^{16}$ found that male sex was an independent risk factor for a shorter interval between pulmonary valve disruption and PVR. However, it is difficult to ascertain whether a true sex-specific difference in the RV response
TABLE 2. Magnetic resonance imaging data for the entire study population $(\mathrm{n}=\mathbf{2 1 8})$

\begin{tabular}{lc}
\hline \multicolumn{1}{c}{ Variable } & Value \\
\hline RV EDVI $\left(\mathrm{mL} / \mathrm{m}^{2}\right)$ & $147 \pm 36$ \\
RV ESVI $\left(\mathrm{mL} / \mathrm{m}^{2}\right)$ & $71 \pm 30$ \\
RV EF $(\%)$ & $53 \pm 9$ \\
PR fraction $(\%)$ & $43 \pm 10$ \\
PR volume $\left(\mathrm{mL} / \mathrm{m}^{2}\right)$ & $32 \pm 12$ \\
LV EDVI $\left(\mathrm{mL} / \mathrm{m}^{2}\right)$ & $76 \pm 12$ \\
LV ESVI $\left(\mathrm{mL} / \mathrm{m}^{2}\right)$ & $29 \pm 8$ \\
LV EF $(\%)$ & $62 \pm 7$ \\
RPA diameter $\left(\mathrm{mm} / \mathrm{m}^{2}\right)$ & $9.0 \pm 2.8$ \\
LPA diameter $\left(\mathrm{mm} / \mathrm{m}^{2}\right) *$ & $7.6 \pm 2.9$ \\
PAI (mm $\left.{ }^{2} / \mathrm{m}^{2}\right)$ & $173 \pm 94$ \\
\hline$R V$, Right ventricular; $E D V I$, end-diastolic volume index; $E S V I$, end-systolic volume \\
index; $E F$, ejection fraction; $P R$, pulmonary regurgitation; $L V$, left ventricular; $R P A$, \\
right pulmonary artery; $L P A$, left pulmonary artery; $P A I$, pulmonary artery index. \\
*Data not available for 3 patients, including 2 patients with interrupted LPA.
\end{tabular}

to chronic volume overload exists, because previous studies found significant sex-specific differences in normal RV volumes, as assessed by MRI. ${ }^{17,18}$ This issue needs to be clarified in future studies.

We found that VSD closure through the right ventricle (transventricular approach) was an independent predictor for RV dilatation and dysfunction. Controversy regarding the optimal surgical technique (eg, transatrial vs transventricular approach) for TOF still exists, ${ }^{19}$ and this has resulted from a lack of long-term follow-up data confirming the superiority of any 1 approach. Lindberg and colleagues, ${ }^{2}$ in their long-term follow-up study, found no differences between transatrial and transventricular repair on survival or repeat repair. ${ }^{2}$ Recently, d'Udekem and colleagues $^{20}$ reported a low risk of PVR for RV dilatation ( $87 \%$ freedom from PVR at 25 years) after a policy of transatrial repair delayed beyond the neonatal period. However, a lack of objective MRI data in their study was a limitation in confirming the superiority of their approach, because the indications for PVR have varied among centers. McKenzie and colleagues ${ }^{21}$ reported that most patients undergoing an "RV infundibulum sparing" approach had an RV EDVI of $<170 \mathrm{~mL} / \mathrm{m}^{2}$ (mean 132) and preserved RV EF as assessed by MRI. However, the median interval to MRI in their study was relatively short (median, 7.9 years). Because a longer interval since repair is a risk factor for $\mathrm{RV}$ dilatation, longer term follow-up data are necessary to confirm the beneficial effects of their approach. One should remember that many technical factors other than the length of RV incision could also influence late outcomes. These factors include the width of the transannular patch (TAP), number of coronary arterial branches sacrificed, extent of infundibular muscle resection, and so forth. It has recently been shown that intersurgeon variability in the long-term outcomes after TOF repair was present, although they followed the same surgical policy. ${ }^{22}$ 
TABLE 3. Predictors for right ventricular end-diastolic volume index $(n=160)$

\begin{tabular}{|c|c|c|c|c|}
\hline \multirow[b]{2}{*}{ Predictor } & \multicolumn{2}{|c|}{ Univariable analysis } & \multicolumn{2}{|c|}{ Multivariable analysis } \\
\hline & $\beta(95 \% \mathbf{C I})$ & $P$ value & $\beta(95 \%$ CI $)$ & $P$ value \\
\hline Male sex & $18.12(6.88,29.36)$ & .002 & $17.55(8.18,26.93)$ & $<.001$ \\
\hline Palliation & $-4.00(-22.63,14.62)$ & .672 & & \\
\hline Age at repair $(y)$ & $0.22(-1.12,1.55)$ & .750 & & \\
\hline TAP & $0.34(-14.78,15.46)$ & .965 & & \\
\hline VSD closure through RV & $11.78(0.35,23.20)$ & .044 & & \\
\hline Interval since repair (y) & $1.25(0.00,2.50)$ & .050 & $1.29(0.27,2.31)$ & .014 \\
\hline RVOTO & $0.48(-20.54,21.50)$ & .964 & & \\
\hline PAI $\left(\mathrm{mm}^{2} / \mathrm{m}^{2}\right)$ & $0.07(0.01,0.13)$ & .031 & & \\
\hline PR fraction $(\%)$ & $1.94(1.44,2.43)$ & $<.001$ & $1.92(1.45,2.40)$ & $<.001$ \\
\hline
\end{tabular}

$C I$, Confidence interval; TAP, transannular patch; $V S D$, ventricular septal defect; $R V$, right ventricle; $R V O T O$, right ventricular outflow tract obstruction; $P A I$, pulmonary artery index; $P R$, pulmonary regurgitation.

A longer interval since repair was independently associated with RV dilatation. This finding was as expected and in accordance with the study by van den Berg and colleagues. ${ }^{23}$ Because a longer interval since repair is a risk factor for RV dilatation, timely PVR before the development of irreversible RV dilatation and dysfunction is of a great clinical concern. ${ }^{7}$ What remains to be elucidated in the future, preferably by serial MRI examinations, is the course of RV dilatation and dysfunction. This will be important to assist in refining the optimal timing of PVR, which is still an issue with many controversies.

We found that a greater PR fraction was independently associated with RV dilatation and dysfunction. The association between the PR fraction and RV volume was expected, because previous studies have demonstrated a close relationship between the degree of PR and the RV volume. ${ }^{4,24}$ In accordance with our finding, other studies have also found that a greater PR fraction was an independent predictor for larger RV volumes. ${ }^{15,23,25}$ However, the association between a greater PR fraction and lower RV EF found in our study has not been demonstrated consistently in previous studies. ${ }^{23-26}$

In our study, a larger PAI was associated with a larger RV EDVI on univariable analysis. Thus, branch pulmonary artery stenosis might be protective against RV dilatation. Our finding is in accordance with those from previous studies. ${ }^{16,27}$ Kogon and colleagues ${ }^{16}$ found that the small branch pulmonary artery diameter lengthened the interval between pulmonary valve disruption and PVR. Maskatia and colleagues ${ }^{27}$ found that bilateral and unilateral branch pulmonary artery stenosis was associated with a lesser PR fraction and smaller RV EDVI than those in patients without stenosis, likely owing to the development of restrictive physiology. ${ }^{7}$ In contrast, other studies have demonstrated that experimentally induced unilateral branch pulmonary artery stenosis resulted in increased PR, in both humans and a swine model. ${ }^{28,29}$ These conflicting results should be interpreted cautiously, because the degree of PR was determined by pulmonary artery compliance and resistance (afterload) proximal or distal to the compliance. ${ }^{10,30,31}$ PR can be exacerbated by increased pulmonary artery compliance and elevated resistance distal to it but can be limited by more proximal resistance.

In our study, the presence of RVOTO at MRI showed a tendency toward a greater RV EF on univariable analysis, although it did not reach statistical significance $(P=.058)$. Previous studies have demonstrated the beneficial effects of residual RVOTO on RV volume and function

TABLE 4. Predictors of right ventricular end-systolic volume index $(n=160)$

\begin{tabular}{|c|c|c|c|c|}
\hline \multirow[b]{2}{*}{ Predictor } & \multicolumn{2}{|c|}{ Univariable analysis } & \multicolumn{2}{|c|}{ Multivariable analysis } \\
\hline & $\beta(95 \% \mathrm{CI})$ & $P$ value & $\beta(\mathbf{9 5} \% \mathbf{C I})$ & $P$ value \\
\hline Male sex & $14.50(4.97,24.03)$ & .003 & $14.08(5.71,22.45)$ & .001 \\
\hline Palliation & $-1.44(-17.18,14.30)$ & .857 & & \\
\hline Age at repair (y) & $-0.28(-1.40,0.85)$ & .627 & & \\
\hline TAP & $0.06(-12.72,12.83)$ & .993 & & \\
\hline VSD closure through RV & $11.68(2.07,21.28)$ & .018 & $8.49(0.08,16.90)$ & .048 \\
\hline Interval since repair (y) & $0.73(-0.34,1.79)$ & .178 & & \\
\hline RVOTO & $-7.75(-25.47,9.97)$ & .389 & & \\
\hline PAI $\left(\mathrm{mm}^{2} / \mathrm{m}^{2}\right)$ & $0.03(-0.02,0.08)$ & .240 & & \\
\hline PR fraction $(\%)$ & $1.44(1.00,1.88)$ & $<.001$ & $1.38(0.95,1.80)$ & $<.001$ \\
\hline
\end{tabular}


TABLE 5. Predictors of right ventricular ejection fraction $(n=160)$

\begin{tabular}{lccc}
\hline & \multicolumn{1}{c}{ Univariable analysis } & \multicolumn{1}{c}{ Multivariable analysis } \\
\cline { 2 - 4 } \multicolumn{1}{c}{ Predictor } & $\boldsymbol{\beta}(\mathbf{9 5} \% \mathbf{C I})$ & $\boldsymbol{P}$ value & $\boldsymbol{\beta}(\mathbf{9 5} \% \mathbf{C I})$ \\
\hline Male sex & $-3.17(-5.91,-0.43)$ & .024 & $-3.10(-5.66,-0.53)$ \\
Palliation & $-0.63(-5.11,3.84)$ & .780 & \\
Age at repair (y) & $0.21(-0.11,0.53)$ & .192 & \\
TAP & $0.26(-3.37,3.89)$ & .887 & \\
VSD closure through RV & $-3.67(-6.38,-0.95)$ & .008 & $-3.05(-5.63,-0.48)$ \\
Interval since repair $(\mathrm{y})$ & $-0.07(-0.38,0.23)$ & .640 & \\
RVOTO & $4.82(-0.17,9.80)$ & .058 & .020 \\
PAI $\left(\mathrm{mm}^{2} / \mathrm{m}^{2}\right)$ & $0.00(-0.02,0.01)$ & .811 & \\
PR fraction $(\%)$ & $-0.29(-0.42,-0.16)$ & $<.001$ & $-0.27(-0.40,-0.14)$ \\
\hline
\end{tabular}

$C I$, Confidence interval; TAP, transannular patch; VSD, ventricular septal defect; $R V$, right ventricle; $R V O T O$, right ventricular outflow tract obstruction; $P A I$, pulmonary artery index; $P R$, pulmonary regurgitation.

in patients with repaired TOF. ${ }^{15,25,32}$ Although we could not demonstrate the beneficial effects of residual RVOTO on the RV volume and function, this might have resulted from the small number of patients with RVOTO $(n=10)$ in our study population. van der Hulst and colleagues ${ }^{13}$

TABLE 6. Comparison between patients with and without PVR

\begin{tabular}{|c|c|c|c|}
\hline Variable & $\begin{array}{c}\text { PVR } \\
(\mathbf{n}=108)\end{array}$ & $\begin{array}{c}\text { No PVR } \\
(n=110)\end{array}$ & $P$ value \\
\hline Male sex & $61(56)$ & $59(54)$ & .673 \\
\hline Palliation & $17(16)$ & $7(6)$ & .027 \\
\hline Age at repair (y) & $4.0 \pm 5.3$ & $2.0 \pm 2.5$ & $<.001$ \\
\hline Type of repair & & & .782 \\
\hline TAP & $83(77)$ & $82(75)$ & \\
\hline Non-TAP & $16(15)$ & $20(18)$ & \\
\hline No information & $9(8)$ & $8(7)$ & \\
\hline Route of VSD closure & & & $<.001$ \\
\hline $\mathrm{RV}$ & $60(56)$ & $38(35)$ & \\
\hline RA & $22(20)$ & $51(46)$ & \\
\hline No information or other & $26(24)$ & $21(19)$ & \\
\hline RVOTO & & & $<.001$ \\
\hline Yes & $8(7)$ & $10(9)$ & \\
\hline No & $98(91)$ & $77(70)$ & \\
\hline No information & $2(2)$ & $23(21)$ & \\
\hline $\begin{array}{l}\text { Interval between repair } \\
\text { and MRI (y) }\end{array}$ & $16.0 \pm 4.9$ & $15.5 \pm 4.7$ & .455 \\
\hline $\operatorname{RV} \operatorname{EDVI}\left(\mathrm{mL} / \mathrm{m}^{2}\right)$ & $162 \pm 38$ & $132 \pm 27$ & $<.001$ \\
\hline $\operatorname{RV} \operatorname{ESVI}\left(\mathrm{mL} / \mathrm{m}^{2}\right)$ & $83 \pm 33$ & $59 \pm 19$ & $<.001$ \\
\hline RV EF (\%) & $50 \pm 9$ & $56 \pm 7$ & $<.001$ \\
\hline $\mathrm{PR}$ fraction $(\%)$ & $46 \pm 9$ & $40 \pm 10$ & $<.001$ \\
\hline PR volume $\left(\mathrm{mL} / \mathrm{m}^{2}\right)$ & $36 \pm 12$ & $29 \pm 11$ & $<.001$ \\
\hline LV EDVI $\left(\mathrm{mL} / \mathrm{m}^{2}\right)$ & $77 \pm 13$ & $74 \pm 11$ & .152 \\
\hline $\operatorname{LV} \operatorname{ESVI}\left(\mathrm{mL} / \mathrm{m}^{2}\right)$ & $31 \pm 9$ & $27 \pm 6$ & .003 \\
\hline $\operatorname{LV} \operatorname{EF}(\%)$ & $61 \pm 7$ & $63 \pm 6$ & .004 \\
\hline $\mathrm{PAI}\left(\mathrm{mm}^{2} / \mathrm{m}^{2}\right)$ & $169 \pm 116$ & $178 \pm 66$ & .488 \\
\hline QRS duration (ms) & $147 \pm 28(\mathrm{n}=62$ & $135 \pm 26(n=79)$ & .010 \\
\hline
\end{tabular}

$P V R$, Pulmonary valve replacement; TAP, transannular patch; $V S D$, ventricular septal defect; $R V$, right ventricle/ventricular; $R A$, right atrium; $R V O T O$, right ventricular outflow tract obstruction; $M R I$, magnetic resonance imaging; EDVI, end-diastolic volume index; $E S V I$, end-systolic volume index; $E F$, ejection fraction; $P R$, pulmonary regurgitation; $L V$, left ventricular; $P A I$, pulmonary artery index. found that postoperative mild residual pulmonary stenosis (peak systolic gradient, $15-30 \mathrm{~mm} \mathrm{Hg}$ ) reduced the risk of PVR during follow-up of patients with corrected TOF. Frigiola and colleagues ${ }^{33}$ found that late survivors of TOF repair who were free from PVR and had a normal exercise capacity were characterized by mild residual RVOTO (peak systolic gradient, $24 \pm 13 \mathrm{~mm} \mathrm{Hg}$ ). The mechanism by which mild residual RVOTO will protect patients against RV dilatation and dysfunction remains unclear. Possibly, the smaller regurgitant orifice area and decreased RV compliance produced by RVOTO might each play a role. ${ }^{30}$ Although the findings of previous studies have stressed the importance of conservative relief of RVOTO in patients with TOF, the optimal degree of "beneficial" RVOTO remains to be determined. Also, it could be difficult to target the optimal degree of RVOTO intraoperatively, because it has previously been shown that a tendency exists for a marked reduction in the transpulmonary gradient for $\leq 6$ months postoperatively. ${ }^{34}$

An interesting finding from our study was that a specific type of repair (TAP vs non-TAP) was not associated with RV dilatation and dysfunction. One should know that preservation of pulmonary valve annulus at TOF repair does not guarantee a competent pulmonary valve. ${ }^{30} \mathrm{~d}$ 'Udekem and colleagues ${ }^{35}$ found no difference between RV and transannular patching with regard to late clinical outcomes (cardiac death, PVR, and impaired functional status), RV size, or incidence of severe PR. The similarity in the outcomes of patients with TAP repair and those with non-TAP repair has also been demonstrated by other studies. ${ }^{13,14} \mathrm{We}$ speculate that these findings resulted because late PR is a consequence of all repair types and not specific only to TAP, except for a small proportion of the patients with the most favorable pulmonary valve morphology.

\section{Study Limitations}

The present study was limited by its retrospective nature. The present study population did not represent the entire spectrum of patients who underwent TOF repair, because 
only those patients who had undergone MRI examination were included. It is possible that a selection bias was present that resulted in important differences between the patients who did and did not undergo MRI, although we could not be sure because we did not have the data to describe the differences between the 2 groups. The patients with any missing data for the potential predictors of RV volumes and function were excluded from the analyses, which might have biased our results. Many surgeons were involved in the repair of our study patients. Therefore, the repair techniques, such as the length of the RV incision, width of the TAP, extent of infundibular muscle resection, and removal of the pulmonary valve leaflets, were not constant. Such technical details could all have influenced the long-term outcomes of our patients.

\section{CONCLUSIONS}

Male sex, VSD closure through the right ventricle, a longer interval since repair, and greater PR fraction were independent predictors of RV dilatation after TOF repair. Male sex, VSD closure through the right ventricle, and greater PR fraction were also independent predictors of $\mathrm{RV}$ dysfunction. Additional studies are necessary to clarify whether residual RVOTO after TOF repair can protect against the deleterious consequences of chronic PR. Understanding the predictors of RV dilatation and dysfunction in patients with repaired TOF is important to refine the clinical counseling, to improve follow-up protocols, and, ultimately, to clarify the optimal surgical management of TOF for better long-term outcomes.

\section{References}

1. Kirsch RE, Glatz AC, Gaynor JW, Nicolson SC, Spray TL, Wernovsky G, et al. Results of elective repair at 6 months or younger in 277 patients with tetralogy of Fallot: a 14-year experience at a single center. J Thorac Cardiovasc Surg. 2014; 147:713-7.

2. Lindberg HL, Saatvedt K, Seem E, Hoel T, Birkeland S. Single-center 50 years experience with surgical management of tetralogy of Fallot. Eur J Cardiothorac Surg. 2011;40:538-42.

3. Bouzas B, Kilner PJ, Gatzoulis MA. Pulmonary regurgitation: not a benign lesion. Eur Heart J. 2005;26:433-9.

4. Lee C, Kim YM, Lee CH, Kwak JG, Park CS, Song JY, et al. Outcomes of pulmonary valve replacement in 170 patients with chronic pulmonary regurgitation after relief of right ventricular outflow tract obstruction: implications for optimal timing of pulmonary valve replacement. J Am Coll Cardiol. 2012;60:1005-14.

5. Ferraz Cavalcanti PE, Sá MP, Santos CA, Esmeraldo IM, de Escobar RR, de Menezes AM, et al. Pulmonary valve replacement after operative repair of tetralogy of Fallot: meta-analysis and meta-regression of 3,118 patients from 48 studies. J Am Coll Cardiol. 2013;62:2227-43.

6. McKenzie ED, Khan MS, Dietzman TW, Guzmán-Pruneda FA, Samayoa AX, Liou A, et al. Surgical pulmonary valve replacement: a benchmark for outcomes comparisons. J Thorac Cardiovasc Surg. February 26, 2014 [Epub ahead of print].

7. Lee C, Lee CH, Kwak JG. Surgical pulmonary valve insertion. Cardiol Young. 2013;23:915-20.

8. Lee C, Park CS, Lee CH, Kwak JG, Kim SJ, Shim WS, et al. Durability of bioprosthetic valves in the pulmonary position: long-term follow-up of 181 implants in patients with congenital heart disease. J Thorac Cardiovasc Surg. 2011;142: 351-8.

9. Oosterhof T, Mulder BJ, Vliegen HW, de Roos A. Cardiovascular magnetic resonance in the follow-up of patients with corrected tetralogy of Fallot: a review. Am Heart J. 2006;151:265-72.
10. Geva T. Repaired tetralogy of Fallot: the roles of cardiovascular magnetic resonance in evaluating pathophysiology and for pulmonary valve replacement decision support. J Cardiovasc Magn Reson. 2011;13:9.

11. Clark TG, Altman DG, De Stavola BL. Quantification of the completeness of follow-up. Lancet. 2002;359:1309-10.

12. Lindsey CW, Parks WJ, Kogon BE, Sallee D III, Mahle WT. Pulmonary valve replacement after tetralogy of Fallot repair in preadolescent patients. Ann Thorac Surg. 2010;89:147-51.

13. van der Hulst AE, Hylkema MG, Vliegen HW, Delgado V, Hazekamp MG, Rijlaarsdam ME, et al. Mild residual pulmonary stenosis in tetralogy of Fallot reduces risk of pulmonary valve replacement. Ann Thorac Surg. 2012;94:2077-83.

14. Hickey EJ, Veldtman G, Bradley TJ, Gengsakul A, Manlhiot C, Williams WG, et al. Late risk of outcomes for adults with repaired tetralogy of Fallot from an inception cohort spanning four decades. Eur J Cardiothorac Surg. 2009;35: 156-64.

15. Spiewak M, Biernacka EK, Małek ŁA, Petryka J, Kowalski M, Miłosz B, et al. Right ventricular outflow tract obstruction as a confounding factor in the assessment of the impact of pulmonary regurgitation on the right ventricular size and function in patients after repair of tetralogy of Fallot. J Magn Reson Imaging. 2011;33:1040-6.

16. Kogon B, Plattner C, Kirshbom P, Kanter K, Leong T, Lyle T, et al. Risk factors for early pulmonary valve replacement after valve disruption in congenital pulmonary stenosis and tetralogy of Fallot. J Thorac Cardiovasc Surg. 2009;138: 103-8.

17. Alfakih K, Plein S, Thiele H, Jones T, Ridgway JP, Sivananthan MU. Normal human left and right ventricular dimensions for MRI as assessed by turbo gradient echo and steady-state free precession imaging sequences. J Magn Reson Imaging. 2003;17:323-9.

18. Maceira AM, Prasad SK, Khan M, Pennell DJ. Reference right ventricular systolic and diastolic function normalized to age, gender and body surface area from steady-state free precession cardiovascular magnetic resonance. Eur Heart J. 2006;27:2879-88.

19. Lee C, Lee CH, Kwak JG, Kim SH, Shim WS, Lee SY, et al. Does limited right ventriculotomy prevent right ventricular dilatation and dysfunction in patients who undergo transannular repair of tetralogy of Fallot? Matched comparison of magnetic resonance imaging parameters with conventional right ventriculotomy long-term after repair. J Thorac Cardiovasc Surg. 2014;147:889-96.

20. d'Udekem Y, Galati JC, Rolley GJ, Konstantinov IE, Weintraub RG, Grigg L, et al. Low risk of pulmonary valve implantation after a policy of transatrial repair of tetralogy of Fallot delayed beyond the neonatal period: the Melbourne experience over 25 years. J Am Coll Cardiol. 2014;63:563-8.

21. McKenzie ED, Maskatia SA, Mery C. Surgical management of tetralogy of Fallot: in defense of the infundibulum. Semin Thorac Cardiovasc Surg. 2013;25: 206-12.

22. d'Udekem Y, Galati JC, Konstantinov IE, Cheung MH, Brizard CP. Intersurgeon variability in long-term outcomes after transatrial repair of tetralogy of Fallot: 25 years' experience with 675 patients. J Thorac Cardiovasc Surg. 2014; 147:880-8.

23. van den Berg J, Hop WC, Strengers JL, de Jongste JC, van Osch-Gevers L, Meijboom FJ, et al. Clinical condition at mid-to-late follow-up after transatrial-transpulmonary repair of tetralogy of Fallot. J Thorac Cardiovasc Surg. 2007; 133:470-7.

24. Geva T, Sandweiss BM, Gauvreau K, Lock JE, Powell AJ. Factors associated with impaired clinical status in long-term survivors of tetralogy of Fallot repair evaluated by magnetic resonance imaging. J Am Coll Cardiol. 2004;43:1068-74.

25. Yoo BW, Kim JO, Kim YJ, Choi JY, Park HK, Park YH, et al. Impact of pressure load caused by right ventricular outflow tract obstruction on right ventricular volume overload in patients with repaired tetralogy of Fallot. J Thorac Cardiovasc Surg. 2012;143:1299-304.

26. Uebing A, Fischer G, Bethge M, Scheewe J, Schmiel F, Stieh J, et al. Influence of the pulmonary annulus diameter on pulmonary regurgitation and right ventricular pressure load after repair of tetralogy of Fallot. Heart. 2002;88:510-4.

27. Maskatia SA, Spinner JA, Morris SA, Petit CJ, Krishnamurthy R, Nutting AC Effect of branch pulmonary artery stenosis on right ventricular volume overload in patients with tetralogy of Fallot after initial surgical repair. Am J Cardiol. 2013;111:1355-60.

28. Chaturvedi RR, Kilner PJ, White PA, Bishop A, Szwarc R, Redington AN Increased airway pressure and simulated branch pulmonary artery stenosis increase pulmonary regurgitation after repair of tetralogy of Fallot: real-time analysis with a conductance catheter technique. Circulation. 1997;95:643-9.

29. Petit CJ, Gillespie MJ, Harris MA, Seymour TL, Liu TY, Khan A, et al. Relief of branch pulmonary artery stenosis reduces pulmonary valve insufficiency in a swine model. J Thorac Cardiovasc Surg. 2009;138:382-9. 
30. Redington AN. Determinants and assessment of pulmonary regurgitation in tetralogy of Fallot: practice and pitfalls. Cardiol Clin. 2006;24:631-9.

31. Kilner PJ, Balossino R, Dubini G, Babu-Narayan SV, Taylor AM, Pennati G, et al. Pulmonary regurgitation: the effects of varying pulmonary artery compliance, and of increased resistance proximal or distal to the compliance. Int J Cardiol. 2009;133:157-66.

32. Latus H, Gummel K, Rupp S, Valeske K, Akintuerk H, Jux C, et al. Beneficial effects of residual right ventricular outflow tract obstruction on right ventricular volume and function in patients after repair of tetralogy of Fallot. Pediatr Cardiol. 2013;34:424-30.

33. Frigiola A, Hughes M, Turner M, Taylor A, Marek J, Giardini A, et al. Physiological and phenotypic characteristics of late survivors of tetralogy of Fallot repair who are free from pulmonary valve replacement. Circulation. 2013;128: 1861-8.

34. Antunes MJ, Castela E, Sanches MF, Melo AS. Preservation of the pulmonary annulus in total correction of tetralogy of Fallot: decreasing transannular gradients in the early follow-up period. Eur J Cardiothorac Surg. 1991;5:528-32.

35. d'Udekem Y, Ovaert C, Grandjean F, Gerin V, Cailteux M, Shango-Lody P, et al. Tetralogy of Fallot: transannular and right ventricular patching equally affect late functional status. Circulation. 2000;102(Suppl 3):III116-22.

\section{Discussion}

Dr Charles D. Fraser (Houston, Tex). I really congratulate Dr Lee and colleagues for this important addition to our body of knowledge concerning the long-term effects of TOF repair on RV performance. This study really was beautifully presented, and I congratulate you on the concise nature of your slides and how clear and instructive they are.

From your original cohort of 251 patients undergoing TOF repair, some by classic RV outflow tract incisions, some by the transatrial/transpulmonary approach, 171 had complete MRI evaluations of RV performance at a mean of 15.5 years after the index correction. In your multivariable analysis for factors associated with late RV dilatation and dysfunction, you found male sex, interval from the original operation, and pulmonary regurgitant fraction to be independent predictors of an increased RV end-diastolic volume index. Of interest, residual RVOTO appears to be protective against RV dilatation and dysfunction.

My questions, first, the goal of the study was to provide additional insight into the treatment of these patients. Based on that premise, how has your thinking now evolved in terms of modifications you will make to the primary operation that you believe will confer long-term protection to RV function?

Dr Lee. Thank you for your excellent comments and question, Dr Fraser.

My institution is performing elective transatrial repair at 3 to 6 months of age for asymptomatic patients, and we prefer primary repair for the younger symptomatic infants. From ours, and other studies, I believe that leaving some degree of RVOTO will be protective against RV dilatation and dysfunction in the long term. However, the optimal degree of RVOTO remains to be determined, and our study could not answer this question. Moreover, it could be difficult to target the optimal degree of RVOTO intraoperatively, because we know that a tendency exists for a significant reduction in the transpulmonary gradient postoperatively. Additional studies are necessary to clarify this issue.

Dr Fraser. So, just to expand on that just a little bit, and I know there will be some other questions, but you would tend to leave a little more obstruction, be a little less liberal with your resection, and, where possible, would you preserve the moderator band?
Dr Lee. Yes, I think it is important to perform less resection of the infundibulum, to leave some degree of RVOTO. In our study, we found that the route of VSD closure was not an independent factor for RV dilatation and dysfunction. Last year, at this meeting, we presented rather disappointing results about limited RV incision in patients who underwent transannular repair. However, the findings of our study should not be interpreted as discouraging the use of the transatrial/transpulmonary approach for TOF repair. We still believe that transatrial/transpulmonary repair of TOF has some role for better long-term outcomes.

Dr Fraser. Just 2 quick more questions then. Tell us your institutional protocol for choosing patients for PVR now. What threshold do you use in terms of the interval from surgery, regurgitant fraction, end-diastolic volume, and so on?

Dr Lee. My institution is rather aggressive toward PVR. Definitely, we recommend PVR for patients with symptoms or exercise intolerance. For the asymptomatic patients - can I go back-this is our recent report about PVR in our center. In this study, the median age at PVR was about 17 years, and we found that PVR should be considered before the RV EDVI exceeded $163 \mathrm{~mL} / \mathrm{m}^{2}$ or the RV end-systolic volume index exceeded $80 \mathrm{~mL} / \mathrm{m}^{2}$ to achieve postoperative normalization of the RV volumes and function. It is difficult to know whether achieving normal RV volumes and function after PVR is absolutely necessary for better long-term outcomes; however, until proved otherwise, we have trying to not exceed these cutoff values for the asymptomatic patients.

However, in practice, it has not always been possible to do this. Sometimes, our cardiologists perform echocardiography and find a severely dilated right ventricle, then they perform the MRI and find a severely, very severely dilated right ventricle, for example, an RV EDVI of $200 \mathrm{~mL} / \mathrm{m}^{2}$. For this patient, I think we would be operating too late.

Therefore, to incorporate these cutoff values into the clinical decision-making process, we should know the course of RV dilatation and dysfunction. Also, I think this can be done by performing serial MRI examinations, and this is an important issue for future studies to assist in refining the optimal timing of PVR.

Dr Fraser. One last question. I cannot resist. So, as those of us who have been married as long as I have know, the male sex is disadvantaged. Why is that so in patients with TOF?

Dr Lee. Our result about the male sex is in accordance with the findings from some previous studies. For example, the Atlanta group reported that male sex was a significant risk factor for a shorter interval between pulmonary valve disruption and PVR. However, it is difficult to ascertain whether true sex-specific differences exist in the RV response to chronic volume overload, because previous studies have reported sex-specific differences in normal RV volumes and function. If our study result is simply a reflection of the sex-specific differences in normal RV volumes, I think we should apply sex-specific criteria for prescribing PVR. Female patients will experience relatively more severe RV dilatation and dysfunction if we use unisex criteria for PVR, and, certainly, this will be an area of future study.

Dr Hillel Laks (Los Angeles, Calif). A question and a comment. First of all, the sex difference could be related to the degree of physical activity in the first 12 years of life, or 14 or 15 or 18 years of life, and males might be much more active during this period than females, but that is just speculation. 
The second point is, I think, it is very important when we talk about MRIs of the right ventricle to differentiate between 2 portions of the right ventricle. The right ventricle has a contractile ejecting lower chamber and an outflow tract. It is not infrequent, and we have seen this in our own institution, where a patient can have a patch that was made transannular with a huge RV aneurysm and pulmonary artery aneurysm. However, the actual contracting chamber below it will not be dilated and will be working extremely well. The MRI personnel who perform these studies include the infundibulum and this aneurysm as part of their volume and in calculating the EF. So, depending on the technique used, you can have an outsized volume and a lower EF in a patient whose actual contractile chamber is still doing extremely well. We try to differentiate that. If it is just the aneurysm issue, because a nontreated pericardial patch was used and was made too large, that does not mean the right ventricle is failing. I assume that in your institution, with close to $80 \%$ TAPs, that the surgeons were extremely careful not to make very large incisions down into the right ventricle and not to use a patch that would expand and cause that to explain your excellent results and the lack of differentiation.

So, I think that until the time comes when we start asking our radiologists and cardiologists who do these calculations to separate these 2 issues, we will not have a good idea on what is actually happening to RV function, in contrast to global issues that are frequently surgeon-related and technique-related.

Dr Lee. Thank you for your comments. I agree with your opinion about the functioning RV trabecular portion and that measuring the RV trabecular portion's volume and function is important. However, I heard from my radiologist that it was not always clear to divide the right ventricle into the trabecular and infundibular portion. That is a problem.

Dr Christoper A. Caldarone (Toronto, Ontario, Canada). Could I just ask, in your multivariable analysis, the RV EF appeared to be associated with some improvement in the face of RVOTO and the hazard ratio was 5.4. What are the units in that hazard ratio? For example, is it expressed in some percentage of change in the EF normalized by some change in the pressure gradient?

Dr Lee. RVOTO was entered into the analysis as yes or no, the presence or absence of RVOTO.

Dr Caldarone. Oh, I see. So, this is a binary association?

Dr Lee. Yes.

Dr Caldarone. So that would be an interesting relationship to study. Rather than creating discrete intervals in the RV outflow tract gradient, the use of this variable as a continuous variable would be informative.

The other point to consider is an interaction term might be present between RVOTO and the regurgitant fraction. A greater regurgitant fraction could be associated with a greater gradient. However, perhaps a gradient is protective, exactly as you said. But, I think those 2 terms really need to be examined carefully for a potential interaction in confounding your analysis.

Dr Lee. We did not examine the relationship between RVOTO and regurgitant fraction, so I cannot answer that question. 